\title{
Knowledge and attitude towards mental disorders among adults in an urban community in south-west Nigeria
}

\author{
Iyanuoluwa O. Mojiminiyi, Mobolanle R. Balogun, Babatunde E. Ogunnowo
}

Department of Community Health and Primary Care, College of Medicine of the University of Lagos, Nigeria

Correspondance; mbalogun@cmul.edu.ng

\begin{abstract}
Background
Mental disorders are one of the most ignored public health issues worldwide. However, the burden associated with mental disorders is ever increasing and poses a major threat to health, social interactions and the economy of both developed and developing countries. Aim

To assess the knowledge of adults residing in an urban local government area in Lagos, south-west Nigeria, with regards to mental health and investigate their attitudes towards this condition.

Methods

This was a descriptive cross-sectional study. Multi-stage sampling was used to select 242 adults who were subsequently interviewed with a structured questionnaire. Data was collected and analysed using Epi Info statistical software version 7 . Associations between sociodemographic variables and the knowledge and attitudes of subjects with regards to mental disorders were assessed using chi-square tests at a significance level of 0.05 .

Results

Almost all respondents (95.5\%) in this study were aware of mental disorders while $31.0 \%$ were related to someone with a mental disorder. Approximately half of the respondents (51.2\%) had poor knowledge of mental disorders while the majority (90.0\%) had positive attitudes. There was a significant and positive association between having a relative with a mental disorder and the level of knowledge $(\mathrm{P}=0.010)$.

Conclusion

Analyses identified knowledge gaps in the community in terms of mental disorders in the community. We recommend that health workers should develop ways to educate the community with regards to the causes, symptoms, effects and treatment options for mental disorders.
\end{abstract}

\section{Abstract}

Key Words: Mental disorders, knowledge, attitude, community, public health, Nigeria

\section{Introduction}

Mental disorders are some of the most commonly ignored public health issues worldwide. The burden associated with these conditions is ever increasing and poses a major threat to health, social interactions, and the economy of both developed and developing countries. According to existing literature, a mental disorder is 'a clinically significant behavioural or psychological syndrome or pattern that occurs in an individual and is associated with present distress or disability or with a significantly increased risk of suffering, death, pain, disability, or an important loss of freedom'1.

There are several different types of mental disorder with varying presentations. These are characterized mainly by a combination of abnormal thoughts, perceptions, emotions, behaviours and relationship with others'. The term 'mental disorders' is an umbrella term that is used to decribe a wide range of illnesses, including anxiety disorders, intellectual and developmental disabilities, including autism, depression, schizophrenia, psychosis, post-traumatic stress disorders and dementia.

In Africa, mental disorders account for approximately 5\% of all reported illnesses and around 1 in 5 inhabitants are reported to suffer with a mental disorder ${ }^{3}$. Furthermore, it is estimated that 200 million Africans may become afflicted by a mental disorder at some point in their lifetime ${ }^{4}$. The prevalence of mental disorders in Nigeria is estimated to be approximately $20 \%$; in other words, around 64 million Nigerians ${ }^{5}$. In Lagos state, the location of the present study, approximately $14.1 \%$ of residents (around 2.5 million) are suffering from a mental disorder ${ }^{6}$.

There are various means of preventing and treating mental disorders and many ways in which we can relieve the suffering these disorders cause. Previous studies have shown that the beliefs and perceptions towards the causes of mental disorders tend to hinder the efficacy of treatment in those that need it, thus exacerbating the severity of the disease ${ }^{7}$. If we are to successfully manage mental disorders, it is vital that we provide appropriate education relating to the causes, prevention and treatment of mental disorders.

The increasing burden of mental disorders in Nigeria, the increasing number of people with mental disorders on the streets, and the potential danger that such people might bring to society, have drawn significant attention and measures are being put in place by the government and private organizations to address these problems. For instance, the federal government has formulated a national policy to ensure that all Nigerians have the right to access good quality mental health services ${ }^{8}$. Significant efforts have also been made to build research capacity to investigate the mental health of children and adolescents? ${ }^{9}$. However, 
people with mental disorders, along with their relatives, still have negative beliefs relating to the causes of their illness. Consequently, it is important that we address this ignorance by providing alternative sources of care and increasing the availability of mental health services ${ }^{3}$. The extent to which patients can benefit from mental health services is known to be affected by the quality and availability of services as well as their knowledge and belief?

This study aimed to investigate the knowledge of adults residing in an urban local government area in Lagos, southwest Nigeria, with regards to mental health and investigate their attitudes towards this condition. By addressing these key questions, it may be possible for us to determine the factors that prevent most of the people affected from seeking medical assistance and therefore develop appropriate measures to address these problems.

\section{Methods}

\section{Study location}

This study was conducted in Kosofe, one of the 16 urban local government areas (LGAs) in Lagos State, south-west Nigeria. Kosofe is located in the northern part of Lagos State and features two local council development areas and seven wards. According to the 2006 National Population Census, Kosofe LGA had a population of 682,772, although the 2015 population was projected to be approximately $1,240,936$ residents ${ }^{10,11}$. Kosofe has 279 streets with a variety of markets, schools, 3 primary health care facilities, and a number of churches and mosques ${ }^{12}$.

\section{Study design and the study population}

This was a descriptive, cross-sectional study that was carried out between April and August 2016. The study participants were adult residents of Kosofe. Residents were included if they were aged 18 years or over and a resident of Kosofe for at least 6 months prior to the study. Any resident that did not fit into these broad criteria were excluded from the study.

\section{Sample size estimation}

The minimum sample size was calculated using the Cochran formula ${ }^{13}$, as shown in Equation (1).

$N=z^{2} p q / d^{2}$

In this equation, $N$ represents the minimum sample size required, $z$. represents the standard deviation with $95 \%$ confidence intervals, $p$ represents the proportion of respondents in a similar study with positive attitude towards mental disorders $(82.7 \%)^{14}$, and $d$ represents the acceptable error margin. By applying a non-response rate of $10 \%$, we calculated that a sample size of 242 residents was required.

\section{Sampling methodology}

Sampling was carried out in five stages. First, two wards were selected from the seven wards in Kosofe Local Government by simple random sampling (balloting). One of the wards has 37 streets while the second has 42 streets. Second, 10 streets were selected from each of the wards by balloting. Third, we identified 12 houses per street and determined the houses that were habitable. Because the streets were so small, we then selected houses consecutively. Houses without an eligible respondent were omitted and the next house was selected. Fourth, when there were multiple households in a single house, we selected a single household by balloting. Finally, one eligible respondent was selected per household. Balloting was used where more than one eligible respondent was present.

\section{Data collection and analysis}

The study proposal was approved by the Health Research and Ethics Committee of the Lagos University Teaching Hospital (LUTH) with approval number: ADM/DCST/ HREC/APP/057. The data collection tool was a structured, interviewer- based questionnaire that was developed from similar studies in the existing literature ${ }^{1,15-19}$. The questionnaire, which contained three sections covering the socio-demographic characteristics of respondents, their knowledge, and their attitude towards mental disorders, was pre-tested on 20 respondents in a similar community. The outcomes of the pre-testing phase were then used to restructure the questionnaire.

Trained interviewers (five medical students) conducted faceto-face interviews over a period of 5 days in June 2016. On average, each interview lasted 20 minutes and was carried out in the homes of the respondents after having previously obtained written informed consent. All respondents participated voluntarily. Confidentiality was maintained by not using identifiers on the questionnaires.

Data was analysed by Epi Info statistical software version 7 (Centers for Disease Control and Prevention, Atlanta, USA). The chi-square test was used to test for associations between variables. Associations were considered to be statistically significant if the $P$-value was less than 0.05 .

The 10 knowledge-based questions ( 5 of which permitted multiple responses) and the 15 attitude-based statements were scored and used to compute overall scores related to knowledge and attitude. For each respondent, we scored knowledge level using scores ranging from 0 to 32 . Each correct answer was awarded 1 mark and each incorrect/don't know answer was awarded a score of 0 . Scores in the range of $0-11(\leq 33.3 \%)$ were categorized as poor knowledge, 12 $22(33.3-66.6 \%)$ as fair knowledge, and 23-32 ( $\geq 66.6 \%)$ as good knowledge.

The attitude of respondents was scored using a five-point Likert scale (options included 'strongly agree', 'agree', 'undecided', 'disagree' and 'strongly disagree'); the most positive option was given a score of 5 and the least positive option was given a score of 1 . The maximum score was 75 and using a cut-off of $50 \%$, scores less than 38 were classified as negative attitude and scores between 39 and 75 were classified as positive attitude.

\section{Results}

A total of 242 questionnaires were given to residents; the response rate was $100 \%$.

\section{Socio-demographic profile}

The mean age of the respondents was 33.1 \pm 11.6 years and the modal age range was $21-30$ years $(38.4 \%)$. The majority of the respondents were male $(52.9 \%)$, married $(52.1 \%)$, Yoruba $(63.6 \%)$ and Christian (76.9\%). Most respondents had attained a tertiary level of education (45.9\%) and $33.9 \%$ of respondents were semi-skilled workers. Only $31.0 \%$ of the respondents knew people with mental disorders (Table $1)$. The majority of the respondents $(95.5 \%)$ had heard about mental disorders prior to the study. The sources of information relating to mental disorders were neighbours $(42.7 \%)$, family members $(28 \%)$, friends $(25.3 \%)$, colleagues at work $(2 \%)$, and church members $(1.3 \%)$. 
Table 1. Socio-demographic characteristics of respondents and their awareness of people with mental disorders

\begin{tabular}{|c|c|}
\hline Variables & Proportion \\
\hline \multicolumn{2}{|l|}{ Age (years) } \\
\hline Less than 20 & $31(12.8)$ \\
\hline $21-30$ & $85(35.1)$ \\
\hline $31-40$ & $70(28.9)$ \\
\hline $41-50$ & $39(16.1)$ \\
\hline $51-60$ & $11(4.6)$ \\
\hline $61-70$ & $4(1.7)$ \\
\hline Sex & $2(0.8)$ \\
\hline Female & $114(47.1)$ \\
\hline Male & $128(52.9)$ \\
\hline \multicolumn{2}{|l|}{ Marital Status } \\
\hline Single & $112(48.3)$ \\
\hline Married & $126(52.1)$ \\
\hline Divorced & $2(0.8)$ \\
\hline Widowed & $2(0.8)$ \\
\hline \multicolumn{2}{|l|}{ Ethnicity } \\
\hline Yoruba & $154(63.6)$ \\
\hline lgbo & $62(25.6)$ \\
\hline Hausa & $10(4.1)$ \\
\hline Delta & $3(1.2)$ \\
\hline Edo & $10(4.1)$ \\
\hline Others & $3(1.2)$ \\
\hline \multicolumn{2}{|l|}{ Highest level of education } \\
\hline No formal education & $7(2.9)$ \\
\hline Primary school & $11(4.6)$ \\
\hline Junior secondary school & $18(7.4)$ \\
\hline Senior secondary school & $95(39.3)$ \\
\hline Tertiary & $111(45.9)$ \\
\hline \multicolumn{2}{|l|}{ Religion } \\
\hline Christianity & $186(76.9)$ \\
\hline Islam & $56(23.1)$ \\
\hline $\begin{array}{l}\text { Occupation of employed } \\
(n=182)\end{array}$ & \\
\hline Senior professional & $19(7.9)$ \\
\hline Intermediate professional & $32(13.2)$ \\
\hline Junior professional & $44(18.2)$ \\
\hline Semi-skilled & $82(33.9)$ \\
\hline Unskilled & $5(2.1)$ \\
\hline \multicolumn{2}{|l|}{$\begin{array}{l}\text { Knows anybody with a mental } \\
\text { disorder }\end{array}$} \\
\hline Yes & $75(31.0)$ \\
\hline No & $167(69.0)$ \\
\hline
\end{tabular}

Table 2. Knowledge of causes, genetic transmission, when mental disorders begin and those most prone to mental disorders

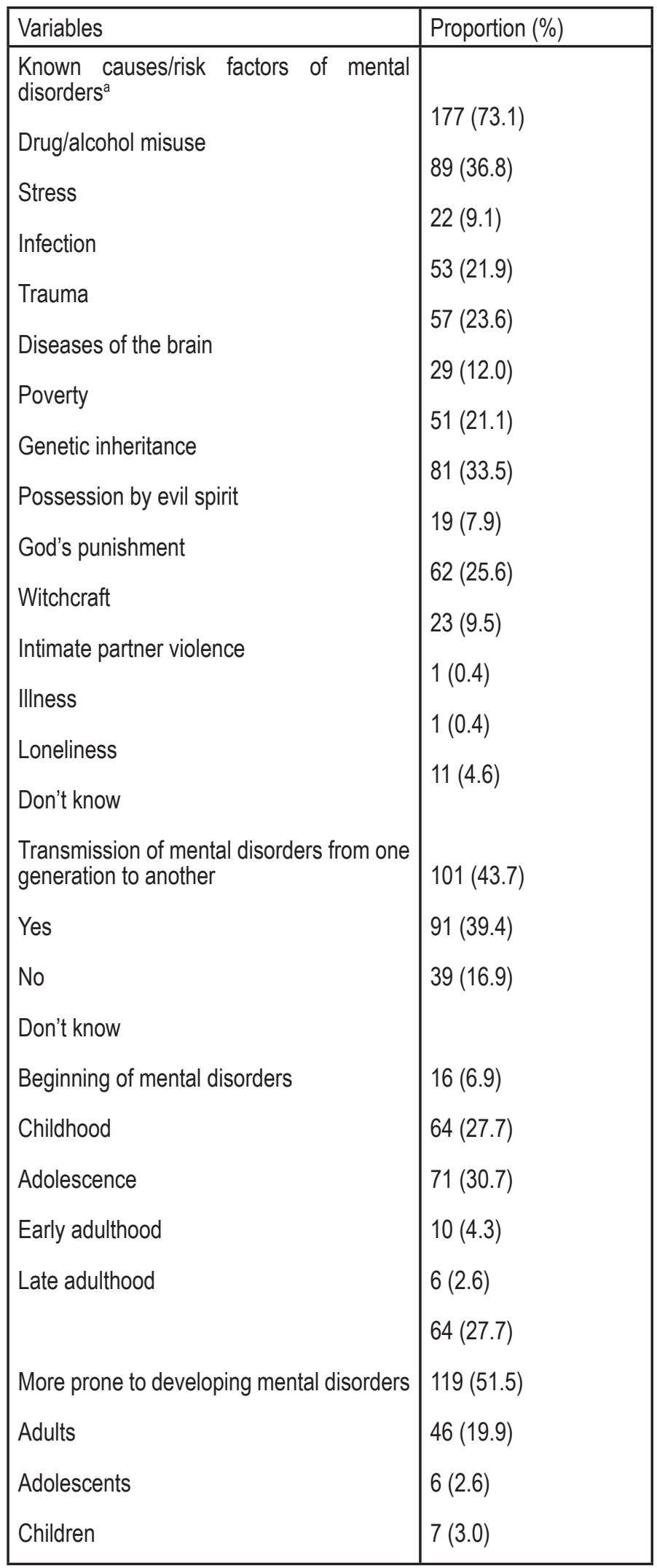

${ }^{a}$ Multiple responses allowed.

\section{Knowledge about mental disorders}

Most of the respondents that had heard of mental disorders identified drug/alcohol misuse $(73.1 \%)$ as the main cause of mental disorders; this was followed by stress $(36.8 \%)$ and then possession by an evil spirit $(33.5 \%)$. A higher proportion of respondents $(43.7 \%)$ knew that mental disorders can be transmitted from one generation to another. Less than half of the respondents $(34.6 \%)$ correctly identified either 
Table 3. Knowledge of symptoms, effects, suicidal tendencies and the treatment of mental disorders

\begin{tabular}{|c|c|}
\hline Variables & Proportion (\%) \\
\hline \multicolumn{2}{|l|}{ Known symptoms of mental disorders ${ }^{a}$} \\
\hline Violence & $70(28.9)$ \\
\hline Loss of contact with reality & $63(26.0)$ \\
\hline Irrational acts & $125(51.7)$ \\
\hline Inappropriate behaviour & $159(65.7)$ \\
\hline Shamelessness & $46(19.0)$ \\
\hline Change in sleeping habit & $35(14.5)$ \\
\hline Change in eating habit & $41(16.9)$ \\
\hline Loss of interests & $29(12.0)$ \\
\hline Guilt & $7(2.9)$ \\
\hline Headaches & $22(9.1)$ \\
\hline Suicidal thoughts & $42(17.4)$ \\
\hline Seeing/hearing strange things & $73(30.2)$ \\
\hline Don't know & $13(5.37)$ \\
\hline \multicolumn{2}{|l|}{ Effects of mental disorders ${ }^{a}$} \\
\hline Impairment of family function & $89(36.8)$ \\
\hline Impairment of mental and physical capacity & $125(51.7)$ \\
\hline Increased level of poverty & $85(35.1)$ \\
\hline $\begin{array}{l}\text { Increased tendency to engage in substance } \\
\text { abuse }\end{array}$ & $94(38.8)$ \\
\hline Premature death & $81(33.5)$ \\
\hline Increased risk of chronic illness & $66(27.3)$ \\
\hline Don't know & $38(15.7)$ \\
\hline \multicolumn{2}{|l|}{ Mental disorders can be treated } \\
\hline Yes & $224(97.0)$ \\
\hline No & $2(0.9)$ \\
\hline Don't know & $5(2.1)$ \\
\hline \multicolumn{2}{|l|}{ Persons who should treat mental disorders } \\
\hline Psychiatrist & $174(75.3)$ \\
\hline Any medical personnel & $14(6.1)$ \\
\hline Religious heads & $12(5.2)$ \\
\hline Traditional healers & $15(6.5)$ \\
\hline Don't know & $16(6.9)$ \\
\hline \multicolumn{2}{|l|}{ Treatment methods ${ }^{a}$} \\
\hline Incantations & $11(4.6)$ \\
\hline Fasting and prayer & $99(40.9)$ \\
\hline Psychotherapy & $106(43.8)$ \\
\hline Use of medication & $136(56.2)$ \\
\hline Rituals & $20(8.3)$ \\
\hline Deliverance & $91(37.6)$ \\
\hline Use of herbs & $3(1.3)$ \\
\hline Don't know & $17(7.0)$ \\
\hline
\end{tabular}

${ }^{a}$ Multiple responses allowed. childhood or adolescence as the period when most mental disorders begin while $51.5 \%$ of respondents knew that adults are more prone to developing mental disorders (Table 2).

The majority of respondents identified inappropriate behaviour $(65.7 \%)$ as a symptom of mental disorders while only $2.9 \%$ identified guilt as a symptom. Half of the respondents $(51.7 \%)$ identified impairment of mental capacity as an effect of mental disorders while $15.7 \%$ could not identify any effect relating to mental disorder. Most of the respondents $(62.8 \%)$ knew that people with mental disorders are at higher risks of committing suicide. Almost all respondents $(97.0 \%)$ knew that mental disorders could be treated; the majority knew that psychiatrists $(75.3 \%)$ should carry out treatments, although $5.2 \%$ chose religious heads. The most preferred method of treatment for mental disorders was the use of medication (56.2\%), followed by psychotherapy (43.8\%); only 1.3\% of respondents identified the use of herbs as the most preferred treatment option (Table 3).

\section{Attitude towards mental disorders}

Almost a third of the respondents (30.3\%) disagreed that a mental disorder is like any other disease, $37.2 \%$ agreed that anybody can have a mental disorder, $58.0 \%$ strongly agreed to advise someone with a mental disorder to visit a psychiatrist, $37.7 \%$ agreed that they would advise someone with a mental disorder to visit a religious leader while $24.2 \%$ disagreed that they would advise someone with a mental disorder to visit a traditional healer. Almost half of the respondents strongly disagreed with the statement that 'doctors that treat people with mental disorders end up having mental disorders.' Most of the respondents $(32.9 \%)$ agreed they could be friends with someone that has a mental disorder while $58.4 \%$ strongly disagreed that they could marry someone with a mental disorder (Table 4). A higher proportion of the respondents $(40.3 \%)$ disagreed that they would be ashamed to mention someone in their family that has a mental disorder, $67.1 \%$ would not share their house/office with someone that has a mental disorder while $34.6 \%$ of respondents agreed that they should not be given any responsibility. Although a large percentage of respondents $(75.3 \%)$ strongly disagreed that people with mental disorders should be killed or left to die and almost half $(49.4 \%)$ of respondents agreed that people with mental disorders should be allowed to live a normal life, $34.6 \%$ agreed that they should be isolated from the rest of the community while $38.5 \%$ agreed that they were violent and should be avoided (Table 4).

\section{Overall knowledge and attitude towards mental disorders}

The mean knowledge score was $11.7 \pm 6.8$ out of a possible score of 32 . Half of the respondents $(51.2 \%)$ had poor knowledge, $43.0 \%$ had fair knowledge while very few (5.8\%) had good knowledge of mental disorders.

The mean attitude score was $50.8 \pm 11.4$ out of a possible score of 75 . Almost all of the respondents $(90.0 \%)$ had a positive attitude towards mental disorders while few $(10 \%)$ had negative attitude towards mental disorders (Table 5).

There was a statistically significant association between knowing a person with a mental disorder and the knowledge level of the respondents as more of the respondents who knew someone with mental disorders had good knowledge $(9.3 \%)$ and fair knowledge $(53.3 \%)$ compared to respondents who did not know someone (4.2\% and $38.3 \%$ respectively). 
Table 4. Attitude of respondents towards mental disorders $(n=231)$

\begin{tabular}{|c|c|c|c|c|c|}
\hline Variable & $\mathrm{SA}(\%)$ & $\mathrm{A}(\%)$ & $U(\%)$ & $\mathrm{D}(\%)$ & $\mathrm{SD}(\%)$ \\
\hline A mental disorder is like any other disease. & $27(11.7)$ & $55(23.8)$ & $13(5.63)$ & $70(30.3)$ & $66(28.6)$ \\
\hline Anybody can have a mental disorder. & $63(27.3)$ & $86(37.2)$ & $14(6.1)$ & $47(20.4)$ & $21(9.1)$ \\
\hline $\begin{array}{l}\text { You would advise anybody with a mental disorder to visit a } \\
\text { psychiatrist. }\end{array}$ & $134(58.0)$ & $70(30.3)$ & $12(5.2)$ & $6(2.6)$ & $9(3.9)$ \\
\hline $\begin{array}{l}\text { You would advise anybody with a mental disorder to visit a } \\
\text { traditional healer. }\end{array}$ & $35(15.2)$ & $51(22.1)$ & $38(16.5)$ & $56(24.2)$ & $51(22.1)$ \\
\hline $\begin{array}{l}\text { You would advise anybody with a mental disorder to visit a } \\
\text { pastor/imam }\end{array}$ & $76(32.9)$ & $87(37.7)$ & $26(11.3)$ & $23(10.0)$ & $19(8.2)$ \\
\hline $\begin{array}{l}\text { Doctors that treat people with mental disorders end up having } \\
\text { mental disorders. }\end{array}$ & $3(1.3)$ & $18(7.8)$ & $24(10.4)$ & $71(30.7)$ & $115(49.8)$ \\
\hline You could be friends with someone with a mental disorder. & $29(12.6)$ & $76(32.9)$ & $30(13.0)$ & $44(19.1)$ & $52(22.5)$ \\
\hline You can marry someone with a mental disorder. & $6(2.6)$ & $11(4.8)$ & $28(12.1)$ & $51(22.1)$ & $135(58.4)$ \\
\hline $\begin{array}{l}\text { You would be ashamed to mention someone in your family } \\
\text { that has a mental disorder. }\end{array}$ & $34(14.7)$ & $41(17.8)$ & $29(12.6)$ & $93(40.3)$ & $34(14.7)$ \\
\hline $\begin{array}{l}\text { You would share your office/house with someone that has a } \\
\text { mental disorder }\end{array}$ & $7(3.0)$ & $47(20.4)$ & $22(9.5)$ & $78(33.8)$ & $77(33.3)$ \\
\hline $\begin{array}{l}\text { People with mental disorders should not be given any } \\
\text { responsibility. }\end{array}$ & $39(16.9)$ & $80(34.6)$ & $14(6.1)$ & $61(26.4)$ & $37(16.0)$ \\
\hline $\begin{array}{l}\text { People with mental disorders should be isolated from the rest } \\
\text { of the community. }\end{array}$ & $22(9.5)$ & $61(26.4)$ & $21(9.1)$ & $80(34.6)$ & $27(20.4)$ \\
\hline $\begin{array}{l}\text { People with mental disorders are violent and should be } \\
\text { avoided. }\end{array}$ & $29(12.6)$ & $89(38.5)$ & $25(10.8)$ & $70(30.3)$ & $18(7.8)$ \\
\hline $\begin{array}{l}\text { People with mental disorders should be allowed to live a } \\
\text { normal life. }\end{array}$ & 44 (19.1) & $114(49.4)$ & $21(9.1)$ & 38 (16.5) & $14(6.1)$ \\
\hline People with mental disorders should be killed/left to die. & $6(2.6)$ & $6(2.6)$ & $5(2.2)$ & $40(17.3)$ & $174(75.3)$ \\
\hline
\end{tabular}

SA, A, U, D and SD represent strongly agree, agree, undecided, disagree and strongly disagree, respectively.

Table 5. Overall knowledge and attitude score of respondents

\begin{tabular}{ll}
\hline Variables & Proportion (\%) \\
\hline Knowledge score & $14(5.8)$ \\
Good & $104(43.0)$ \\
Fair & $124(51.2)$ \\
Poor & $11.7 \pm 6.8$ \\
Mean \pm SD & \\
Attitude score & $208(90.0)$ \\
Positive & $23(10.0)$ \\
Negative & $50.8 \pm 11.4$ \\
\hline
\end{tabular}

(Table 6). However, there was no statistically significant association between socio-demographic variables and the overall attitude of the respondents.
Table 6: Association between socio-demographic variables and overall knowledge level

\begin{tabular}{|c|c|c|c|c|c|c|}
\hline \multirow{2}{*}{$\begin{array}{l}\text { S o c i o - } \\
\text { demographic } \\
\text { variables }\end{array}$} & \multirow[b]{2}{*}{ Poor } & \multicolumn{2}{|c|}{ Overall knowledge } & \multirow[t]{3}{*}{$x^{2}$} & \multirow[t]{3}{*}{ df } & \multirow[t]{3}{*}{$P$-value } \\
\hline & & Fair & Good & & & \\
\hline & Prop. (\%) & Prop. $(\%)$ & Prop. (\%) & & & \\
\hline \multicolumn{7}{|c|}{$\begin{array}{l}\text { Age group } \\
\text { (years) }\end{array}$} \\
\hline 10 & $15(48.4)$ & $14(45.2)$ & $2(6.5)$ & & & \\
\hline 0100 & $52(61.2)$ & $27(31.8)$ & $6(7.1)$ & & & \\
\hline $31-10$ & $31(44.3)$ & $37(52.9)$ & $2(2.9)$ & & & \\
\hline & $18(46.2)$ & $18(46.2)$ & $3(7.7)$ & 15.78 & 12 & 0.202 \\
\hline & $4(36.4)$ & $6(54.6)$ & $1(9.1)$ & & & \\
\hline $31-00$ & $4(100.0)$ & $0(0.0)$ & $0(0.0)$ & & & \\
\hline$>70$ & $0(0.0)$ & $2(100.0)$ & $0(0.0)$ & & & \\
\hline Sex & & & & & & \\
\hline Male & $59(46.1)$ & $62(48.4)$ & $7(5.5)$ & 3.34 & 2 & 0.189 \\
\hline Female & $65(57.0)$ & $42(36.8)$ & $7(6.1)$ & & & \\
\hline
\end{tabular}




\section{Table 6 Cont....}

Marital status

\begin{tabular}{|c|c|c|c|c|c|c|}
\hline Single & $60(53.6)$ & $43(38.4)$ & $9(8.0)$ & & & \\
\hline Married & $61(48.4)$ & $60(47.6)$ & $5(4.0)$ & & & \\
\hline Divorced & $2(100.0)$ & $0(0.0)$ & $0(0.0)$ & & & \\
\hline Widowed & $1(50.0)$ & $1(50.0)$ & $0(0.0)$ & 5.24 & 6 & 0.514 \\
\hline \multicolumn{7}{|l|}{ Ethnicity } \\
\hline Yoruba & $82(53.3)$ & $65(42.2)$ & $7(4.6)$ & & & \\
\hline lgbo & $27(43.6)$ & $29(46.8)$ & $6(9.7)$ & & & \\
\hline Hausa & $5(50.0)$ & $4(40.0)$ & $1(10.0)$ & & & \\
\hline Delta & $2(66.7)$ & $1(33.3)$ & $0(0.0)$ & & & \\
\hline Edo & $7(70.0)$ & $3(30.0)$ & $0(0.0)$ & & & \\
\hline Others & $1(33.3)$ & $2(66.7)$ & $0(0.0)$ & 3.19 & 4 & 0.527 \\
\hline \multicolumn{7}{|c|}{$\begin{array}{l}\text { Highest level of } \\
\text { education }\end{array}$} \\
\hline No formal & $4(57.1)$ & $3(42.8)$ & $0(0.0)$ & & & \\
\hline education & $2(18.2)$ & $9(81.9)$ & $0(0.0)$ & & & \\
\hline Primary school & $12(66.7)$ & $4(22.2)$ & $2(11.1)$ & & & \\
\hline Junior secondary & $55(57.9)$ & $3(37.9)$ & $4(4.2)$ & & & \\
\hline school & $51(46.0)$ & $52(46.9)$ & $8(7.2)$ & 14.00 & 8 & 0.082 \\
\hline
\end{tabular}

Senior secondary

school

\begin{tabular}{|c|c|c|c|c|c|c|}
\hline \multicolumn{7}{|l|}{ Tertiary education } \\
\hline Christianity & $91(48.9)$ & $83(44.6)$ & $12(6.5)$ & & & \\
\hline Islam & $33(58.9)$ & $21(37.5)$ & $2(3.6)$ & 1.97 & 2 & 0.374 \\
\hline \multicolumn{7}{|l|}{$\begin{array}{l}\text { Occupation of the } \\
\text { employed }\end{array}$} \\
\hline 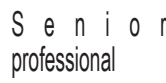 & $6(31.6)$ & $12(63.2)$ & $1(5.3)$ & & & \\
\hline Intermediate & $13(40.6)$ & $17(53.1)$ & $2(6.3)$ & & & \\
\hline $\begin{array}{l}\text { J u n i } \\
\text { professional }\end{array}$ & $\begin{array}{l}23(52.3) \\
50(61.0)\end{array}$ & $\begin{array}{l}20(45.5) \\
30(36.6)\end{array}$ & $1(2.3)$ & & & \\
\hline Semi-skilled & $4(80.0)$ & $1(20.0)$ & $0(0.0)$ & 9.72 & 8 & 0.286 \\
\hline \multicolumn{7}{|l|}{ Unskilled } \\
\hline \multicolumn{7}{|l|}{$\begin{array}{l}\text { Knows anybody } \\
\text { with a mental } \\
\text { disorder }\end{array}$} \\
\hline Yes & $28(37.3)$ & $40(53.3)$ & $7(9.3)$ & & & \\
\hline No & $96(57.5)$ & $64(38.3)$ & $7(4.2)$ & 9.18 & 2 & 0.010 \\
\hline
\end{tabular}

\section{Discussion}

In this study, the commonest causes of mental disorders identified by respondents that had heard of mental disorders were drug/alcohol misuse $(73.1 \%)$, stress $(36.8 \%)$ and possession by evil spirits $(33.5 \%)$. Our data were similar to those arising from a previous study in Pakistan where drug/ alcohol misuse $(72.9 \%)$ and stress $(51 \%)$ were identified as the predominant causes of mental disorders. ${ }^{20}$ Our data were also similar to those arising from a study conducted in Malawi where almost all respondents $(95 \%)$ attributed causes of mental disorders to drug and alcohol misuse. However, a large number of respondents $(82.8 \%)$ in this previous study attributed the cause to possession by evil spirits ${ }^{16}$; this finding was very different from our current study. Other studies, also performed in Nigeria, indicated that drug and alcohol misuse were major causes of mental disorders ${ }^{14,21}$.

Most of the respondents in this study knew that mental disorders could be transmitted from one generation to another $(43.7 \%)$, including schizophrenia, bipolar disorder and depression. This finding was similar to a study performed in Zambia, where most respondents knew that mental disorders could be transmitted ${ }^{22}$. Unlike this study, a previous study performed in Kaduna State, Nigeria, showed that most of the respondents $(89.2 \%)$ did not know that mental disorders can be transmitted genetically ${ }^{18}$. Results from the present study have, therefore, demonstrated that there has been a clear improvement in knowledge relating to the transmission of mental disorders.

In this study, $27.7 \%$ and $6.9 \%$ of respondents knew that mental disorders usually begin in adolescence or childhood, respectively. This is consistent with a previous study performed in Dang, Nepal, where $27.3 \%$ of respondents knew that mental disorders begin in adolescents ${ }^{23}$. The potential danger of not being aware of mental disorders in adolescence and childhood can bring about a delay in seeking medical attention, thereby worsening the prognosis of such disorders. This can also increase the risk of stigmatization by peers and therefore expose such people to a higher risk of committing suicide.

Almost all the respondents in this study $(94.6 \%)$ could identify at least one symptom associated with mental disorders. This result demonstrates an improvement in knowledge relating to the symptoms of mental disorders compared to studies performed in Southern India and Cameroon where 60\% and $51.9 \%$ of respondents, respectively, successfully identified causes of mental disorders ${ }^{24,25}$. This proves that more people can identify the manifestations of a mental disorder and seek help, thereby reducing the burden associated with mental disorders in Nigeria.

Our study showed that $62.8 \%$ of respondents knew that people with mental disorders are at higher risk of committing suicide. A previous study, carried out in Nepal, also showed similar results with $58.0 \%$ of respondents identifying impairment of mental and physical capacity, impairment of family function, or exacerbation of poverty, as effects of mental disorders; moreover, $48.9 \%$ of respondents knew that people with mental disorders are at high risk of engaging in substance abuse ${ }^{23}$. In this same study, $69.3 \%$ of respondents correctly identified that people with mental disorders are at higher risks of committing suicide ${ }^{23}$.

Almost all of the respondents in the present study (97.0\%) knew that mental disorders could be treated and the majority of respondents chose psychiatrists $(75.3 \%)$ as the most appropriate form of initial treatment. A study conducted in Southern India showed that $42 \%$ of respondents knew about the treatment of mental disorders ${ }^{24}$ while another study conducted in north-east India showed that psychiatrists (57.4\%) were the most preferred treatment option for 
mental disorders ${ }^{26}$. Another study, conducted in Nepal, also reported similar results, with $86 \%$ of respondents choosing psychiatrists as the most preferred treatment option for mental disorders; $7 \%$ chose general practitioners and $1 \%$ chose local faith healers ${ }^{27}$. Unlike this study, a study performed in Delta State, Nigeria, in 2009, showed that 87.2\% of respondents thought that mental disorders could not be treated ${ }^{21}$. Consequently, our present study demonstrates a clear improvement in knowledge relating to the treatment of mental disorders.

Almost all respondents $(93.0 \%)$ could identify at least one treatment method. The most commonly identified treatment methods were the use of drugs $(56.2 \%)$ and psychotherapy $(43.8 \%)$. These findings are similar to a study performed in Saudi Arabia where $72.9 \%$ of respondents identified the use of drugs as the most preferred treatment option ${ }^{28}$. Unlike the present study, those performed previously in southern India, Cameroon and south-western Nigeria showed that respondents had poor knowledge of treatment methods as only $42 \%, 30.4 \%$ and $29 \%$, respectively, could correctly identify methods for treating mental disorders. ${ }^{24,25,29}$. Our present study shows there has been drastic improvement in knowledge relating to the treatment of mental disorders, thus showing that general awareness of this condition has increased markedly. This will further help to reduce the burden and threat that mental disorders pose on individuals and the society at large.

Most respondents $(58.9 \%)$ disagreed that a mental disorder is like any other disease, although the majority of respondents $(64.5 \%)$ agreed that anybody can have a mental disorder. These findings are similar to those of a previous study conducted in Malaysia where $78.1 \%$ of respondents disagreed that a mental disorder is like any other disease ${ }^{30}$. A study conducted in Hong Kong showed that $79 \%$ of respondents agreed that anybody could develop a mental disorder $^{31}$. Another study, carried out in Saudi Arabia, reported that $55 \%$ of respondents agreed that anyone could develop a mental disorder ${ }^{28}$; these previous findings differ from the results obtained in this study.

In this study, almost all of the respondents $(90 \%)$ had a positive attitude towards mental disorders. Similar findings were reported by previous studies carried out in China (70$80 \%)^{32}$, Pakistan ${ }^{20}$, Nepal (urban, 69.3\%; rural, 63.5\%) ${ }^{19}$ and Malawi $(91.9 \%)^{16}$. However, different findings were reported by previous studies performed in Ethiopia ${ }^{33}, \mathrm{Zambia}^{22}$, and several other states of Nigeria ${ }^{14,18,21,34}$ in which most of the respondents had negative attitudes.

From a general point of view, many people are now coming to realize that a mental disorder is a medical condition that needs to be treated just like every other physical ailment. Our data showed that this was also reflected in their attitudes as more people had positive attitudes. This means that there has been a reduction in stigmatization. We believe that such stigmatization can be totally eradicated if medical workers provide appropriate educational strategies to improve awareness.

Previous studies have shown that people who have had contact with the mentally ill tend to have more knowledge, as well as a better attitude, towards those with mental disorders ${ }^{26,32}$. This correlates with our current findings as most of the respondents with good knowledge about mental disorders knew someone that had a mental disorder, although this had no correlation with their attitude towards them.
This study had some limitations that need to be considered. Firstly, the questionnaire, although pre-tested and revised to avoid ambiguity and confusion, was not subjected to further validation. Secondly, the sample size was small compared to the that of the community; this may have compromised the generalizability of the results within the study area.

\section{Conclusion}

Our study showed that almost half of ourrespondents (48.8\%) had fair to good knowledge of mental disorders. However, there were some gaps in knowledge, as only a few of our respondents could correctly identify the causes, symptoms, effects and treatment modalities of mental disorders. Most respondents $(90.0 \%)$ had a positive attitude towards mental disorders as most agreed that mental disorders are like other diseases and that anybody can develop a mental disorder. It is recommended that health workers should educate the community on the causes, symptoms, effects and appropriate treatment options for mental disorders.

\section{Conflict of interest}

None of the authors have any conflicts of interest to declare.

\section{Authors' contribution}

Iyanuoluwa Mojiminiyi and Mobolanle Balogun participated in study conceptualization, methodology, formal analysis and writing of original draft. Babatunde Ogunnowo participated in the methodology and critical review and editing of original draft.

\section{Funding}

No specific funding was received for this study.

\section{Acknowledgements}

The authors express their gratitude to Amusa Omolabake, Oladunjoye Olayinka, Ojo Folashade, Olagbaiye Funmilayo, Bamido Borowa and Izge Micheal who assisted with data collection and analysis.

\section{References}

1. Stein DJ, Phillips KA, Bolton D, Fulford KW, Sadler JZ, Kendler KS. What is a mental/psychiatric disorder? From DSM-IV to DSM-V Psychol Med. 2010;40(11):1759-65. doi:10.1017/S0033291709992261.

2. WHO. Mental Disorders [cited 2016 March 8]. Available from: http:// www.who.int/entity/mediacentre/factsheets/fs $381 / \mathrm{en} /-42 \mathrm{k}$.

3. Department for International Development. DFID Research: Considering mental health in Africa; 2013 [cited 2016 March 16]. Available from: https://www.gov.uk/government/news/dfid-researchconsidering-mental-health-in-africa.

4. Spooner S. Mental illness, Africa's 'invisible' health challenge. 2014 [cited 2016 March 8]. Available from: http://mgafrica.com/article/201406-24-mental-illness-africas-invisible-health-challenge

5. Oyewunmi AE, Oyewunmi OA, Iyiola OO, Ojo AY. Mental health and the Nigerian workplace: fallacies, facts and the way forward. Int J Psychol Couns. 2015;7(7):106-11.

6. Mental Health Leadership and Advocacy Programme (mhLAP). Mental Health Situation Analysis in Nigeria. 2012 Report summary [cited 2016 March 8]. Available from: https://www.google.com/ url? sa=t\&source=web\&rct=http://www.mhlap.org/jdownloads/ mhlap\%25202012/menta_lhealth_situation_analysis_in_nigeria.doc\& ved=2ahUKEwjZ9Yazw JjdAhVID 8 AKHV3 A104ChAWMAd6AgAE AE\&usg=AOvVaw3BG_5w5YNZaFW6Aqus59bR

7. Ganasen KA, Parker S, Hugo CJ, Stein DJ, Emsley RA, Seedat S. Mental health literacy: Focus on developing countries. Afr J Psychiatry. 2008;11(1):23-8. 
8. Federal Ministry of Health. National Policy for Mental Health Services Delivery. Federal Ministry of Health, Abuja, Nigeria, 2013. [cited 2018 March 20]. Available from: http://cheld.org/wp-content/ uploads/2015/02/national_policy_for_mental_health_service_ delivery_2013_.pdf.

9. Omigbodun OO, Belfer ML. Building research capacity for child and adolescent mental health in Africa. Child Adolesc Psychiatry Ment Health. 2016;10(1):27. doi:10.1186/s13034-016-0119-2.

10. Geoview, Kosofe [cited 2016 April 6] Available from: http:/ ng.geoview.info/kosofe, 787129 .

11. Lagos Bureau of Statistics. Abstract of local government statistics: Lagos state government, 2013.pg 4-5 [cited 2016 April 6]. Available from: http://www.lagosstate.gov.ng/2013_Digest $\% 20$ of_Statistics.pdf

12. Kosofe Local Government Area [cited 2018 Sept 1]. Available from: https://kosofelocalgovtarea.blogspot.com/?m=1

13. University of Florida, Electronic Data Information Source. Determining sample size. [cited 2016 March]. Available from: http:/ edis.ifas.ufl.edu/m/Epublication?id $=$ PD 006

14. Ukpong DI, Abasiubong F. Stigmatising attitudes towards the mentally ill: a survey in a Nigerian university teaching hospital. S Afr J Psychiatry. 2010;16(2):56-60. doi: 10.4102/sajpsychiatry.v16i2.238.

15. Gureje O, Olley B.O, Ephraim-Oluwanuga O, Kola L. Do beliefs about causation influence attitudes to mental illnesses? World Psychiatry. 2006;5(2):104-7.

16. Crabb J, Stewart RC, Kokota D, Masson N, Chabunya S, Krishnadas R. Attitudes towards mental illnesses in Malawi: a cross-sectional survey. BMC Public Health. 2012;12:541. doi:10.1186/1471-2458-12541.

17. Ehiemua S. Mental disorder: Mental health remains an invisible problem in Africa. EJRRES. 2014;2(4):11-16.

18. Audu IA, Idris SH, Olisah VO, Sheikh TL. Stigmatisation of people with mental illness among inhabitants of a rural community in northern Nigeria. Int J Soc Psychiatry. 2013;59(1):55-60. doi: $10.1177 / 0020764011423180$

19. Singh B, Singh R, Singh KK. Knowledge and attitude towards mental health and mental illness: An issue among rural and urban community of Jhapa District of Nepal. Int J Health Sci Res. 2013;3(9):29-34.

20. Waqas A, Zubair M, Ghulam H, Ullah MW, Tariq Z, Arshad M et al. Exploring the knowledge and attitudes of Pakistani university students towards mental illnesses. Peer J PrePrints. 2014;454(1):1-20. doi:10.7287/preprints.454v1

21. Ewhrudjakpor C. Knowledge, beliefs and attitudes of health care providers towards the mentally ill in Delta State, Nigeria. Ethno-Med. 2009;3(1):19-25. doi: 10.1080/09735070.2009.11886332.

22. Kapungwe A, Cooper S, Mwanza J, Mwape L, Sikwese A, Kakuma
$\mathrm{R}$, et al. Mental illness-stigma and discrimination in Zambia. Afr J Psychiatry (Johannesbg). 2010;13(3):192-203.

23. Das R, Adhikari P, Sharma B. Knowledge, attitude and practice survey of community people regarding mental illness: evidence from Dang District of Nepal. JYMR 2013;1(1):1-5.

24. Ganesh K. Knowledge and attitude of mental illness among general public of southern India. Natl J Community Med. 2011;2(1):175-178.

25. Yongsi HBN. Knowledge and attitudes towards mental health and mental illness among general public in Yaounde. SAS J Med. 2015;1(1):26-32.

26. Longkumer I, Borooah IP. Knowledge about and attitude towards mental disorders among Nagas in North East India. IOSR J Humanit Soc Sci. 2013;1(4)5:41-7 doi: 10.9790/0837-1544147

27. Gurung G. Knowledge and attitude of nurses regarding mental illness. J Chitwan Med College. 2014;4(8):40-43. doi:10.3126/jcmc. v4i2.10863

28. Elbur AI, Albarraq AA, Yousif MA, Abdallah MA, Aldeeb ID. Relatives' perception on mental illnesses, services and treatment, Taif, Saudi Arabia. W J Pharm Pharm Sci. 2014;3(2):969-980.

29. Adewuya A, Makanjuola R. Preferred treatment for mental illness among Southwestern Nigerians. Psychiatr Serv. 2009;60(1):121-4. doi: 10.1176/appi.ps.60.1.121

30. Ng J, Zaidun S, Hong S, Tahrin M, Yong JA, Khan A. Determining the attitudes of a rural community in Penang, Malaysia towards mental illness and community-based psychiatry care. Internet $\mathrm{J}$ Third World Med. 2009;9(1):1-6.

31. Siu BW, Chow KK, Lam LC, Chan WC, Tang VW, Chui WW. A questionnaire survey on attitudes and understanding towards mental disorders. East Asian Arch Psychiatry. 2012;22(1):18-24.

32. Yan Tang AC. Cross sectional survey: public attitude toward mental illness in China. Int Arch Nurs Health Care. 2015;1(1):1-4. doi: 10.23937/2469-5823/1510025.

33. Bedaso A, Yeneabat T, Yohannis Z, Bedasso K, Feyera F. Community attitude and associated factors towards people with mental illness among residents of Worabe Town, Silte Zone, southern nation's nationalities and people's region Ethiopia. PLoS One. 2016;11(3):e0149429. doi: 10.1371/164journal.pone.0149429.

34. Adewuya AO, Makanjuola RO. Social distance towards people with mental illness in Southwestern Nigeria. Aust N Z J Psychiatry. 2008;42(5):389-95. doi: 1080/00048670801961115. 